\title{
KAJIAN TERJEMAHAN KALIMAT YANG MEREPRESENTASIKAN TINDAK TUTUR ASERTIF MENJAWAB DALAM DUA VERSI TERJEMAHAN NOVEL PRIDE AND PREJUDICE
}

\author{
Paramita Widya Hapsari, M. R. Nababan, Djatmika \\ Magister Linguistik Program Pascasarjana UNS \\ paramitawh10@gmail.com
}

\begin{abstract}
Background: This research is conducted by analyzing answering speech acts in Pride and Prejudice (PAP) novel and its two translation versions, Shira Media and Qanita Publisher. The aims of this research are to describe: (1) observing or non-observing the maxim, (2) the translation techniques used for translating answering speech acts in PAP novel and its two translation versions, (3) the translation quality of answering speech acts in PAP novel and its two translation versions, (4) the impacts of translation techniques toward the quality of answering speech acts in PAP novel.

Method: This is a descriptive-qualitative research. The source of data are documents, PAP novel; and informants who assessed the quality of the translations. The data are answering speech acts in PAP novel and the information about translation quality given by the informants. The techniques of data collection are content analysis, questionaire, and Focus Group Discussion (FGD).

Result: It is found out that there are observing and non-observing the maxim used in answering speech acts in PAP novel and its two translation versions. In Shira Media Publisher, the translation techniques used are: established equivalence, variation, borrowing, amplification (explicitation), amplification (addition), reduction, modulation, adaptation, transposition, literal, discursive creation, particularization, and generalization. Established equivalence and variation techniques commonly appear in observing and non-observing maxim quantity. These techniques also produce accurate and acceptable translations. Meanwhile, there are 11 translation techniques used in Qanita Publisher are: established equivalence, variation, borrowing, amplification (explicitation), amplification (addition), modulation, reduction, discursive creation, adaptation, transposition, and particularization. Same as the novel Shira Media Publisher, established equivalence and variation techniques also commonly appear in observing and non-observing maxim.

Conclusion: The research findings in this research show that established equivalence technique has positive impact to translation quality. Meanwhile, literal and discursive creation are technique that produce less accurate and less acceptable translation. However, the findings also show the majority of translation techniques used are able to create accurate and acceptable translations.
\end{abstract}

Keywords: cooperative principles, translation techniques, translation quality. 


\begin{abstract}
ABSTRAK
Latar Belakang: Penelitian ini dilakukan dengan menganalisis tuturan menjawab dalam novel Pride and Prejudice (PAP) dan dua versi terjemahannya, yaitu dari Penerbit Shira Media dan Qanita. Tujuan penelitian ini adalah untuk mendeskripsikan: (1) pematuhan dan pelanggaran maksim prinsip kerjasama (PK), (2) teknik penerjemahan yang dipakai untuk menerjemahkan tuturan menjawab dalam dua versi novel terjemahan PAP, (3) kualitas terjemahan tuturan menjawab dalam dua versi novel terjemahan PAP, (4) dampak penggunaan teknik penerjemahan terhadap kualitas terjemahan tuturan menjawab novel PAP.

Metode: Penelitian ini merupakan penelitian deskriptif-kualitatif. Sumber data penelitian ini adalah dokumen berupa novel Pride and Prejudice; dan juga informan yang menilai kualitas terjemahan. Data dalam penelitian ini adalah tuturan menjawab dalam novel Pride and Prejudice dan informasi mengenai kualitas terjemahan yang diberikan para informan. Teknik pengumpulan data dilakukan dengan analisis dokumen, kuesioner, dan Focus Group Discussion (FGD).

Hasil: Ditemukan bahwa tuturan menjawab dalam novel PAP dan dua versi terjemahannya menggunakan pematuhan dan pelanggaran maksim PK. Terdapat 13 teknik penerjemahan pada novel Penerbit Shira Media, yaitu: kesepadanan lazim, variasi, peminjaman, amplifikasi (eksplisitasi), amplifikasi (penambahan), reduksi, modulasi, adaptasi, transposisi, harfiah, kreasi diskursif, partikularisasi, dan generalisasi. Mayoritas teknik kesepadanan lazim dan variasi muncul pada pematuhan maksim PK dan pelanggaran maksim PK kuantitas. Teknik tersebut juga menghasilkan terjemahan akurat dan berterima. Terdapat 11 teknik penerjemahan pada novel Penerbit Qanita, yaitu: kesepadanan lazim, variasi, peminjaman, amplifikasi (eksplisitasi), amplifikasi (penambahan), modulasi, reduksi, kreasi diskursif, adaptasi, transposisi, dan partikularisasi. Sama seperti pada novel Penerbit Shira Media, teknik kesepadanan lazim dan variasi juga merupakan teknik yang banyak digunakan dalam pematuhan maksim PK dan pelanggaran maksim PK.

Kesimpulan: Temuan dalam penelitian ini menunjukkan bahwa teknik yang berdampak positif terhadap kualitas terjemahan adalah teknik kesepadanan lazim, sedangkan teknik harfiah dan kreasi diskursif merupakan teknik yang menghasilkan terjemahan dengan kualitas yang kurang baik. Namun, mayoritas teknik penerjemahan memiliki andil positif terhadap kualitas terjemahan tuturan menjawab, baik pada Penerbit Shira Media maupun Qanita.
\end{abstract}

Kata Kunci: maksim prinsip kerjasama, teknik penerjemahan, kualitas terjemahan

\title{
PENDAHULUAN
}

Saat berkomunikasi, manusia selalu bertindak tutur melalui ucapan-ucapan mereka untuk mengungkapkan suatu maksud, perasaan, pendapat, dan pikiran mereka. Melalui ujaran tersebut, penutur dapat mempengaruhi mitra tuturnya untuk melakukan apa yang ia maksud. Suatu makna atau maksud tuturan tersebut dapat terjadi ialah 
karena adanya penutur, situasi tutur, dan struktur dalam bahasa itu sendiri. Ketika seseorang berbicara, mereka tidak hanya menghasilkan ujaran yang mengandung kalimat gramatikal (kalimat tanya, kalimat perintah, kalimat pernyataan) saja, tetapi juga melakukan tindakan melalui ucapan mereka. Bahkan pada tataran kata pun mampu mengungkapkan suatu maksud di dalamnya. Ujaran-ujaran yang demikian itu disebut dengan tindak tutur (speech act).

Tindak tutur adalah cara untuk berkomunikasi. Dalam ujaran tersebut mengandung suatu tindakan. Tindak tutur membahas tentang makna tutur atau maksud (intention) yang terkandung dalam suatu tuturan. Menurut Yule (1996:47) "Actions performed through utterances are called speech acts". Selain itu, menurut Griffiths (2006:148): "These basic units of linguistic interaction - such as give a warning to, greet, apply for, tell what, confirm an appointment - (the acts, not the labels) are called speech acts”.

Dengan kata lain, tindak tutur merupakan tindakan yang dilakukan melalui tuturan seseorang, atau tuturan yang dimaksudkan agar mitra tutur atau pendengar melakukan sesuatu. Dengan melakukan tindak tutur, penutur mencoba untuk menyampaikan maksud dan tujuan berkomunikasi kepada lawan tuturnya dengan harapan lawan tuturnya memahami apa yang dimaksud. Tindak tutur tidak hanya berfungsi sebagai pembentuk kata-kata, tetapi juga memiliki makna lain dibalik katakata yang diucapkan oleh penutur, seperti yang dikatakan oleh Austin (1962) dalam bukunya How to Do Things with Words.

Tindak tutur dibedakan menjadi berbagai aspek, yaitu maksud penutur dan bagaimana penutur mencoba mempengaruhi mitra tuturnya untuk melakukan sesuatu. Situasi dimana ucapan tersebut diucapkan akan mempengaruhi penafsiran yang berbeda 
oleh mitra tutur atau pendengarnya. Selanjutnya, Austin (1962) membedakan tindak tutur menjadi tiga jenis, yaitu tindak lokusi (an act of saying something), tindak ilokusi (an act of doing something), dan tindak perlokusi (an act of affecting something). Lokusi adalah semata-mata tindak berbicara, yaitu tindak mengucapkan sesuatu dengan kata dan kalimat sesuai dengan makna kata itu (di dalam kamus) dan makna kalimat itu sesuai dengan kaidah sintaksisnya. Ilokusi adalah hal tertentu yang dimaksudkan atau ingin dicapai dari suatu tindak tutur. Perlokusi mengacu pada efek yang ditimbulkan oleh tindak tutur yang dihasilkan. Lebih lanjut Searle (1979:21), membagi tindak ilokusi berdasarkan fungsinya menjadi 5 kategori, yaitu assertives (asertif), directives (direktif), commissives (komisif), expressives (ekspresif) dan declarations (deklarasi). Asertif adalah tindak tutur yang mengikat penuturnya kepada kebenaran atas apa yang dikatakannya. Direktif merupakan tindak tutur yang dimaksudkan agar lawan tutur melakukan tindakan yang disebutkan dalam ujaran. Komisif merupakan tindak tutur yang mengikat penuturnya untuk melakukan apa yang disebutkan dalam ujaran. Ekspresif adalah tindak tutur yang dimaksudkan untuk mengekspresikan atau mengungkapkan sikap psikologis penutur. Yang terakhir deklarasi ialah tindak tutur yang dilakukan penutur dengan maksud untuk menciptakan hal (termasuk di dalamnya status dan keadaan) yang baru. Dalam penelitian ini hanya difokuskan pada salah satu tindak tutur, yaitu tindak tutur asertif menjawab (answering). Yule (1996:93) menjelaskan bahwa tindak tutur asertif merupakan tindak tutur yang mengikat penuturnya akan kebenaran atas apa yang diujarkan dan bertujuan untuk memberikan informasi kepada mitra tutur. Dengan kata lain, tindak tutur asertif merupakan tindak tutur yang disampaikan oleh penutur kepada mitra tuturnya bahwa mereka mengetahui atau mempercayai sesuatu dan sesuatu tersebut ialah suatu fakta atau berkaitan dengan 
fakta. Yang termasuk verba asertif antara lain yaitu menyatakan (stating), menjawab (answering), menyarankan (suggesting), membual (boasting), mengeluh (complaining), mengklaim (claiming), dan sebagainya. Tindak tutur menjawab merupakan salah satu tindak tutur yang digunakan oleh penutur untuk merespon suatu pertanyaan dari mitra tuturnya. Namun terkadang dalam prakteknya, penutur merespon pertanyaan mitra tuturnya tidak selalu tepat atau apa adanya. Mereka terkadang memberi jawaban yang kurang, lebih, atau bahkan tidak ada hubungannya. Dalam hal ini, peneliti juga tertarik untuk meneliti pelanggaran maksim kerjasama (cooperative principles) yang terdapat dalam tuturan menjawab. Grice (dalam Birner 2013:41) mengungkapkan bahwa

"The Cooperative Principle: make your conversational contribution such as is required, at the stage at which occurs, by the accepted purpose or direction of the talk exchange in which you are engaged".

Selanjutnya, Grice menjelaskan bahwa di dalam Prinsip Kerjasama penutur harus mematuhi empat maksim. Maksim ialah prinsip yang harus ditaati oleh peserta tutur dalam berinteraksi dalam upaya melancarkan jalannya proses komunikasi. Prinsip Kerjasama yang diungkapkan oleh Grice terdiri atas empat maksim, yaitu maksim kuantitas (quantity), maksim kualitas (quality), maksim relevansi (relation), dan maksim cara (manner). Maksim kuantitas menghendaki setiap peserta pertuturan memberikan kontribusi yang secukupnya atau sebanyak yang dibutuhkan oleh lawan bicaranya atau pembicara memberikan informasi yang cukup, relatif dan seinformatif mungkin. Maksim kualitas mewajibkan setiap peserta percakapan mengatakan sesuatu yang nyata dan sesuai dengan fakta sebenarnya. Kontribusi peserta percakapan hendaknya didasarkan pada bukti-bukti yang memadai. Apabila patuh pada prinsip ini, jangan pernah mengatakan sesuatu yang diyakini bahwa itu kurang benar atau tidak 
benar. Maksim relevansi mengharuskan setiap peserta tutur dapat memberikan kontribusi yang relevan/sesuai dengan sesuatu yang sedang dipertuturkan. Maksim pelaksanaan mengharuskan setiap peserta percakapan berbicara secara langsung, tidak kabur, tidak taksa, dan tidak berlebih-lebihan, serta runtut. Selain itu, ada empat cara mitra tutur menanggapi Prinsip Kerjasama tersebut. Birner (2013:42) menjelaskan empat cara itu ialah observe the maxims, violate a maxim, flout a maxim, dan opt out of the maxims. Selanjutnya, peneliti akan mengidentifikasi teknik apa saja yang digunakan dalam tuturan menjawab tersebut dengan menggunakan teori Molina \& Albir (2002), lalu menilai kualitas terjemahannya menggunakan teori Nababan dkk (2012) yang difokuskan hanya pada keakuratan dan keberterimaan.

\section{METODE PENELITIAN}

\section{Lokasi Penelitian}

Lincoln dan Guba dalam Santosa (2014:40) menjelaskan bahwa lokasi penelitian sebagai "focus determined boundary”, yang secara harfiah berarti batas yang ditentukan oleh fokus atau objek penelitian. Spradley dalam Santosa (2014:40) menambahkan bahwa dalam lokasi penelitian, elemen utamanya adalah setting, participant, dan event. Lokasi penelitian (setting) dalam penelitian ini adalah novel Pride and Prejudice karya Jane Austen dan terjemahannya. Participant dalam novel ini adalah semua tokoh yang terlibat dalam novel tersebut. Event dalam penelitian ini adalah tuturan menjawab dari para tokoh di novel Pride and Prejudice. 


\section{Sumber Data dan Data}

Sumber data merupakan asal diperolehnya data. Penelitian ini menggunakan dua jenis sumber data yaitu dokumen dan informan. Sumber data yang berupa dokumen adalah novel Pride and Prejudice dan dua versi terjemahannya karya Jane Austen. Sedangkan data yang berupa informan terkumpul melalui bantuan para rater yang menilai kualitas terjemahan.

Data yang digunakan dalam penelitian ini meliputi data primer dan data sekunder. Data primer penelitian ini adalah tindak tutur asertif menjawab dalam novel Pride and Prejudice beserta dua versi terjemahannya dalam bahasa Indonesia yang berjumlah 135 data serta kuesioner penilaian kualitas terjemahan oleh rater. Sementara itu, yang tergolong data sekunder adalah segala informasi dan dokumen yang terkait dengan penelitian.

\section{Sampling}

Penelitian ini menggunakan purposive sampling technique atau disebut juga criterion-based sampling technique, yaitu yang didasarkan atas tujuan penelitian. Oleh sebab itu, sample yang diambil yaitu berdasarkan kriteria-kriteria tertentu dan lebih selektif sehingga sesuai dengan apa yang dibutuhkan dalam penelitian ini. Hal ini dimaksudkan untuk memperoleh kedalaman dan kelengkapan data dalam menghadapi realitas serta untuk memperoleh kedalaman studi di dalam konteks tertentu (Sutopo, 2002:36-37). Dalam hal ini, data yang digunakan adalah tindak tutur asertif menjawab dalam dua versi novel terjemahan Pride and Prejudice.

Sedangkan untuk kriteria rater, rater haruslah seseorang yang memiliki keahlian dalam bidang penerjemahan, memiliki pemahaman tentang kajian pragmatik, 
menguasai bahasa Indonesia dan bahasa Inggris dengan baik, serta bersedia berpartisipasi dalam penelitian ini.

\section{Teknik Pengumpulan Data}

Berdasarkan jenis data yang digunakan dalam penelitian ini, teknik pengumpulan data yang sesuai adalah analisis dokumen, kuesioner, dan focus group discussion. Data yang berupa dokumen diperoleh melalui analisis dokumen. Pertama, penulis membaca novel Pride and Prejudice tersebut, sambil mencatat tindak tutur tindak tutur asertif menjawab beserta terjemahannya, juga memahami konteks situasi pada novel tersebut. Kemudian penulis mengklasifikasikan tindak tutur asertif menjawab tersebut berdasar teori maksim Prinsip Kerjasama (Cooperative Principle). Peneliti juga melihat apakah tuturan menjawab tersebut mematuhi (observing) atau melanggar (non-observing) maksim Prinsip Kerjasama. Selanjutnya, penulis menganalisis teknik penerjemahan yang diterapkan penerjemah dan terakhir melihat dampak dari pemilihan teknik penerjemahan terhadap kualitas terjemahan dari dua novel terjemahan.

Kuesioner dalam penelitian ini bertujuan untuk mendapatkan data tentang tingkat keakuratan dan keberterimaan. Kuesioner bersifat terbuka (open-ended quesioner), yang artinya bahwa peneliti memberikan kesempatan kepada rater (informan) untuk memaparkan atau memberikan penjelasan, pendapat, alasan, maupun pernyataan atas data yang diberikan. Selanjutnya, untuk menggali alasan penilaian para rater atas kualitas terjemahan secara lebih obyektif dan akurat, peneliti mengadakan focus group discussion. 


\section{Teknik Analisis Data}

Data yang telah terkumpul dianalisis secara induktif sesuai dengan ciri metode kualitatif yang datanya dikumpulkan satu persatu untuk menyusun teori yang utuh. Tahapan analisa data yang digunakan dalam penelitian ini diambil dari tahapan analisis data menurut Spradley (2007) yang meliputi domain, taxonomy, componential, dan finding cultural values.

Yang pertama, analisis domain. Pada tahap ini data dipisahkan dari yang bukan data. Selanjutnya, analisis taksonomi, yaitu semua data yang berupa tindak tutur asertif dikumpulkan dan diklarifikasikan berdasarkan kategorinya. Analisis taksonomi pertama dilakukan dengan menganalisis data berdasarkan teori maksim Prinsip Kerjasama dan selanjutnya menganalisis teknik penerjemahan dan kualitas terjemahannya. Setelah penggolongan data dalam analisis taksonomi, tindak tutur dan teknik penerjemahannya dianalisis tingkat kualitas terjemahannya yang meliputi tingkat keakuratan dan keberterimaan, juga keterkaitannya satu sama lain melalui analisis komponensial. Terakhir, analisis tema budaya. Pada tahap ini penulis melihat mengapa tindak tutur asertif menjawab dalam dua versi novel yang berjudul Pride and Prejudice yang diterjemahkan ke dalam bahasa Indonesia memiliki tingkat keakuratan dan keberterimaan yang tinggi atau sebaliknya. Sehingga akan terlihat jelas kaitan teoritis antara tingkat kualitas terjemahan; yaitu tingkat keakuratan dan keberterimaan, dengan tindak tutur asertif menjawab yang ada dalam dua versi novel terjemahan Pride and Prejudice. 


\section{HASIL DAN PEMBAHASAN}

Pada tahap analisis tuturan menjawab yang ada dalam novel Pride and Prejudice, peneliti menemukan 135 data pada masing-masing novel terjemahan yang mengandung tindak tutur menjawab. Analisis pemilihan tindak tutur menyarankan sebagai data dalam penelitian ini didasarkan pada kriteria pemilihan data, yakni berupa tuturan yang dikategorikan sebagai tindak tutur menjawab. Konteks situasi dalam novel Pride and Prejudice juga turut digunakan untuk menentukan apakah tuturan tersebut merupakan tindak tutur menjawab. Tuturan bertanya juga merupakan konteks situasi untuk mendukung kejelasan tindak tutur menjawab tersebut. Data tindak tutur menjawab sebanyak 135 data tersebut kemudian dianalisis berdasarkan teori Maksim Prinsip Kerjasama. Peneliti menemukan dua cara Maksim Prinsip Kerjasama (PK), yaitu Mematuhi Maksim PK (Observing the maxim) dan Tidak Mematuhi atau Melanggar Maksim PK (Non-observing the maxim).

Temuan dari kedua cara Maksim PK dalam novel Pride and Prejudice tersebut adalah sebagai berikut: (1) mematuhi Maksim PK sebanyak 46 data atau 34,1\%, (2) melanggar Maksim PK sebanyak 89 data atau 65,9\%. Pelanggaran Maksim PK (Non-observing the maxim) menjadi cara dominan yang ditemukan dalam dua novel terjemahan Pride and Prejudice dibandingkan pematuhan Maksim PK. Hal ini disebabkan karena novel tersebut merupakan novel yang menyoroti kelas sosial masyarakat pada zaman itu, dimana suatu kedudukan dan harga diri seseorang sangatlah dianggap penting dan merupakan sesuatu yang harus dijaga bagi setiap orang. Oleh karena itu, beberapa tokoh di novel Pride and Prejudice secara tidak sadar melanggar Maksim PK dengan misalnya berbohong, mengatakan sesuatu yang berlebihan, menyembunyikan sesuatu saat menjawab pertanyaan dari mitra tuturnya. Dengan 
begitu, tokoh tersebut dapat mempertahankan kewibawaan dirinya di depan mitra tutur yang menanyakan sesuatu kepadanya. Berikut merupakan tablel yang menunjukkan temuan cara maksim PK.

Tabel 1. Cara Maksim Prinsip Kerjasama pada Tindak Tutur Menjawab dalam Novel

\begin{tabular}{ccc}
\multicolumn{3}{c}{ Pride and Prejudice } \\
\hline Cara Maksim PK & $\sum$ & $\%$ \\
\hline $\begin{array}{c}\text { Mematuhi maksim PK } \\
\text { (Observing) }\end{array}$ & 46 & $34,1 \%$ \\
$\begin{array}{c}\text { Tidak mematuhi maksim } \\
\text { PK (Non-observing) }\end{array}$ & 89 & $65,9 \%$ \\
\hline
\end{tabular}

\section{Pematuhan Maksim Prinsip Kerjasama}

Kaidah-kaidah bertutur sangat diperlukan pada saat peserta tutur melakukan pertuturan. Salah satu kaidah tersebut adalah Prinsip Kerjasama. Karena penelitian ini mengkaji tentang tindak tutur menjawab, maka pematuhan maksim prinsip kerjasama berarti penutur menjawab pertanyaan mitra tutur sesuai dengan apa yang ditanyakan oleh mitra tutur, tidak ada pengurangan atau pun penambahan, juga tidak ada ketidakjelasan dalam menjawab. Contoh data yang termasuk dalam observing the maxim dapat dilihat dari contoh data berikut ini:

$\mathrm{BSu} \quad$ : "You begin to comprehend me, do you?"

"Oh! yes-I understand you perfectly."

$\mathrm{BSa}_{1} \quad$ : "Kau mulai membaca kepribadianku, ya?"

"Oh ya! Aku benar-benar memahamimu."

$\mathrm{BSa}_{2}$ : "Kau sudah mulai memahamiku, bukan?" seru Bingley menatap Elizabeth.

"Oh ya! Aku sangat memahamimu."

Contoh di atas merupakan tuturan menjawab yang mematuhu maksim PK. Hal ini dapat dilihat dari tuturan Elizabeth yang menjawab "Oh! yes-I understand you perfectly." pada BSu. Jawaban tersebut sudah cukup jelas dan sesuai dengan porsinya. 
Elizabeth tidak memberikan informasi yang tidak dibutuhkan oleh Mr.Bingley. Tidak ada yang dikurangi atau pun ditambahkan dari jawaban tersebut.

Dalam hal penggunaan teknik penerjemahan pada data yang mematuhi maksim PK ditemukan setidaknya teknik kesepadanan lazim, peminjaman murni, variasi, amplifikasi (penambahan), amplifikasi (eksplisitasi), reduksi, adaptasi, modulasi, partikularisasi, dan kreasi diskursif. Dari beragam jenis teknik tersebut, teknik kesepadanan lazim adalah teknik yang mendominasi dalam temuan data yang tergolong mematuhi maksim PK. Terjemahan tuturan menjawab dengan kualitas terbaik dihasilkan novel dari Penerbit Qanita. Hal tersebut dikarenakan jarang ditemukan adanya distorsi makna. Selain itu, setiap tuturan menjawab dapat ditransfer dengan baik ke dalam bahasa sasaran. Di sisi lain, novel Penerbit Shira Media yang menghasilkan terjemahan berterima dibandingkan Penerbit Qanita, namun hanya terpaut 1 data saja.

\section{Pelanggaran Maksim Prinsip Kerjasama}

Tabel 2. Pelanggaran Maksim Prinsip Kerjasama (Non-observing the maxim) pada Tindak Tutur Menjawab dalam Novel Pride and Prejudice

\begin{tabular}{clcc}
\hline \multirow{2}{*}{$\begin{array}{c}\text { Pelanggaran Maksim } \\
\text { PK }\end{array}$} & $\sum$ & \% \\
\hline Flouting & Kuantitas & 40 & $44,9 \%$ \\
\cline { 2 - 4 } & Kualitas & 3 & $3,4 \%$ \\
\cline { 2 - 4 } & Relevansi & 34 & $38,3 \%$ \\
\cline { 2 - 4 } & Cara & 5 & $5,6 \%$ \\
\hline Violating & Kuantitas & 1 & $1,1 \%$ \\
\cline { 2 - 4 } & Kualitas & - & - \\
\cline { 2 - 4 } & Relevansi & 1 & $1,1 \%$ \\
\cline { 2 - 4 } & Cara & - & - \\
\hline Multiple & & 5 & $5,6 \%$ \\
\hline \multicolumn{2}{c}{ TOTAL } & $\mathbf{8 9}$ & $\mathbf{1 0 0 \%}$ \\
\hline
\end{tabular}

Pelanggaran maksim PK dapat terjadi dalam sebuah percakapan ketika informasi yang ingin disampaikan oleh penutur kepada mitra tutur tidak tersampaikan dengan baik. 


\section{Pelanggaran Flouting Maksim Kuantitas}

Berikut merupakan salah satu contoh data yang termasuk dalam observing the maxim flouting kuantitas:

BSu : "Can I have the carriage?"

"No, my dear, you had better go on horseback, because it seems likely to rain; and then you must stay all night."

$\mathrm{BSa}_{1} \quad$ : "Boleh aku naik kereta?"

"Tidak, sayang, kau sebaiknya pergi dengan menunggang kuda, karena kelihatannya sebentar lagi hujan akan turun. Dengan begitu kau bisa menginap disana."

$\mathrm{BSa}_{2} \quad$ : "Bolehkah aku menaiki kereta?"

"Tidak, sayangku, hari ini cuaca sedang mendung. Sebaiknya kau menunggang kuda. Dengan begitu, kau bisa menginap di sana bila hujan turun."

Contoh di atas termasuk dalam pelanggaran maksim kuantitas. Hal tersebut terjadi karena jawaban tersebut secara kuantitas berlebihan. Dalam konteks situasi tersebut, Jane bertanya kepada Mrs.Bennet apakah ia boleh menggunakan kereta kuda untuk pergi ke kediaman Mr.Bingley. Jawaban yang Jane perlukan ialah hanya "No, my dear..." pada tuturan awal Mrs.Bennet. Namun dapat dilihat bahwa Mrs.Bennet menambah jawabannya, sehingga membuat jawaban menjadi berlebihan dan keluar dari topik pembicaraan.

Pelanggaran maksim flouting kuantitas pada dua versi novel terjemahan tersebut menggunakan 9 jenis teknik penerjemahan, yaitu: kesepadanan lazim, adaptasi, amplifikasi (penambahan dan eksplisitasi), modulasi, reduksi, peminjaman murni, variasi, dan transposisi. Kesembilan teknik tersebut cenderung menghasilkan terjemahan yang akurat dan berterima.

\section{Pelanggaran Flouting Maksim Kualitas}

BSu : "Your examination of Mr.Darcy is over, I presume. And pray what is the result?" "I'm perfectly convinced by it that Mr.Darcy has no defect. He owns it himself without disguise."

$\mathrm{BSa}_{1}$ : "Pengamatanmu atas Mr.Darcy sudah selesai, kurasa," ucap Miss Bingley, "dan apakah hasilnya?"

"Aku betul-betul yakin bahwa Mr.Darcy tidak punya kelemahan. Kalaupun ada, dia menyembunyikannya dengan rapi sekali." 
$\mathrm{BSa}_{2} \quad$ : "Pemeriksaanmu atas Mr.Darcy sudah selesai, sepertinya" kata Miss Bingley, "dan apakah hasilnya?"

"Aku yakin sepenuhnya bahwa Mr.Darcy tidak memiliki kelemahan. Kalaupun ada, dia menyembunyikannya dengan sangat baik."

Pada tuturan menjawab tersebut terlihat bahwa Elizabeth sangat mengagumi Mr.Darcy dengan semua sifatnya. Namun faktanya, ia mengatakan hal seperti itu karena ia masih mencari tahu sifat asli sepenuhnya dari Mr.Darcy. ia dengan sengaja berbohong, yaitu dengan sengaja memberikan pernyataan yang tidak benar.

Pelanggaran maksim flouting kualitas pada novel Penerbit Shira Media menggunakan 6 jenis teknik penerjemahan, yaitu: kesepadanan lazim, modulasi, peminjaman murni, adaptasi, variasi, dan amplifikasi (eksplisitasi). Sementara itu, pada novel Penerbit Qanita menggunakan 4 jenis teknik penerjemahan, yaitu: kesepadanan lazim, peminjaman murni, variasi, dan amplifikasi (eksplisitasi). Dalam hal keakuratan dan keberterimaan, kedua penerbit menghasilkan terjemahan yang cukup akurat dan berterima.

\section{Pelanggaran Flouting Maksim Relevansi}

$\mathrm{BSu} \quad$ : "I cannot see that London has any great advantage over the country, for my part, except the shops and public places. The country is a vast deal pleasanter, is it not, Mr. Bingley?"

"When I am in the country, I never wish to leave it; and when I am in town it is pretty much the same. They have each their advantages, and I can be equally happy in either."

$\mathrm{BSa}_{1} \quad$ : "Saya tidak melihat London punya banyak kelebihan di banding desa, kecuali pertokoan dan tempat-tempat umum. Desa ini lebih menyenangkan dibandingkan London, bukan begitu, Mr.Bingley?"

"Sewaktu saya tinggal di desa, saya tidak pernah sedetik pun 2 berniat untuk meninggalkannya; dan sewaktu saya ada di kota, saya juga merasakan hal serupa. Desa dan $\underline{\text { kota }}_{3}$ punya kelebihan masing-masing, dan saya senang-senang saja tinggal di dua tempat itu."

$\mathrm{BSa}_{2} \quad$ : "Menurut saya, tidak banyak kelebihan daripada wilayah pedesaan, kecuali toko-toko dan tempat-tempat umumnya. Desa jauh lebih menyenangkan, bukan begitu, Mr.Bingley?'

"Ketika saya berada di desa, saya tidak pernah berkeinginan meninggalkannya. Dan, hal yang kurang lebih sama terjadi saat saya berada di kota. Kota dan desa 2 memiliki kelebihannya masing-masing, dan saya sama senangnya berada di keduanya."

Pada contoh di atas, Mr.Bingley menjawab pertanyaan Mrs. Bennet yang tidak ada hubungannya dengan pertanyaan sebelumnya. Hal tersebut membuat topik 
pembicaraan bergeser dan keluar dari intinya dan menyebabkan jawaban tersebut melanggar maksim relevansi.

Teknik yang digunakan pada pelanggaran maksim relevansi sebanyak 11 jenis teknik penerjemahan pada kedua penerbit. Namun pada Penerbit Shira Media, terdapat teknik generalisasi yang digunakan penerjemah, sedangkan pada Penerbit Qanita, terdapat teknik kreasi diskursif. Pada pelanggaran maksim relevansi ini, terjemahan yang dihasilkan dari kedua penerbit juga tergolong cukup baik, yakni sebagian besar data menghasilkan terjemahan akurat dan berterima.

\section{Pelanggaran Flouting Maksim Cara}

BSu : "Do you talk by rule, then, while you are dancing?"

"Sometimes. One must speak a little, you know. It would look odd to be entirely silent for half an hour together; and yet for the advantage of some, conversation ought to be so arranged, as that they may have the trouble of saying as little as possible."

$\mathrm{BSa}_{1} \quad$ : "Apakah ada aturan untuk berbicara sewaktu sedang berdansa?"

"Terkadang memang begitu. Kita mesti berbicara sedikit sewaktu sedang berdansa. Akan aneh sekali kalau pasangan dansa membisu selama setengah jam menghabiskan waktu bersama. Tapi demi kepentingan sebagian orang, percakapan harus diatur sedemikian rupa karena pasangan dansa barangkali mengalami masalah dalam berbicara."

$\mathrm{BSa}_{2} \quad$ : "Apakah ada aturan untuk berbicara saat sedang berdansa?"

"Kadang-kadang. Kita harus sedikit berbicara saat sedang berdansa. Akan sangat aneh jika pasangan dansa diam saja selama setengah jam menghabiskan waktu bersama. Namun, demi kepentingan sebagian orang, percakapan harus diatur sedemikian rupa, karena pasangan dansa mungkin mengalami masalah dalam berbicara."

Dapat dilihat pada contoh di atas bahwa jawaban Mr.Darcy tidak jelas dan seakan berputar-putar. Pada konteks data di atas, sebenarnya Elizabeth sedikit menyindir Mr.Darcy tentang adanya aturan saat berdansa, namun Mr.Darcy tidak terlalu memperhatikan dan menjawabnya dengan kabur. Hal tersebut membuat data tersebut tergolong sebagai data yang melanggar maksim cara.

Ditemukan sebanyak 5 jenis teknik penerjemahan pada kedua penerbit dalam menerjemahkan tuturan menjawab yang tergolong pelanggaran flouting maksim cara. 
Teknik tersebut adalah kesepadanan lazim, modulasi, variasi, amplifikasi (penambahan), dan harfiah. Penggunaan teknik-teknik tersebut juga mempengaruhi kualitas terjemahan, yaknik terjemahan yang akurat dan berterima.

\section{Pelanggaran Violating Maksim Kuantitas}

BSu : "May I hope, madam, for your interest with your fair daughter Elizabeth, when I solicit for the honour of a private audience with her in the course of this morning?"

"Oh dear!-yes -certainly. I am sure Lizzy will be very happy—I am sure she can have no objection. Come, Kitty, I want you up stairs."

$\mathrm{BSa}_{1} \quad$ : "Madam, berkaitan dengan putri Anda yang cantik, Elizabeth, apakah Anda mengizinkan saya untuk berbicara secara pribadi dengannya pagi ini?"

"Oh. Ya, tentu saja. Aku yakin Lizzy akan senang sekali. Aku yakin dia tidak akan keberatan. Ayo, Kitty, mari kita ke atas."

$\mathrm{BSa}_{2}$ : "Madam, sehubungan dengan putri Anda yang cantik, Elizabeth, apakah Anda mengizinkan saya untuk berbicara secara pribadi dengannya pagi ini?"

"Oh! Ya - tentu saja. Saya yakin Lizzy akan sangat senang - saya yakin dia tidak akan keberatan. Ayo, Kitty, mari kita ke atas."

Pada contoh di atas, jawaban "certainly" tersebut sebenarnya digunakan

Mrs.Bennet untuk menutupi kegugupannya yang sebenarnya ia tidak mengizinkan

Mr.Collins untuk menemui Elizabeth. Hal tersebut membuktikan bahwa sebenarnya Mrs.Bennet tidak mengatakan hal yang sebenarnya dan hanya untuk menutupi sesuatu yang diniatkan.

Sebanyak 2 jenis teknik penerjemahan diaplikasikan penerjemah untuk menerjemahkan tuturan menjawab yang ada di dua penerbit, yaitu teknik kesepadanan lazim dan reduksi. Dari kedua penerbit, ditemukan 1 data yang tergolong violating maksim kuantitas dan keduanya menghasilkan terjemahan akurat dan berterima.

\section{Pelanggaran Violating Maksim Relevansi}

$\mathrm{BSu} \quad$ : "Is it possible? Can it be possible that he will marry her?"

"Wickham is not so undeserving, then, as we thought him. My dear father, I congratulate you."

$\mathrm{BSa}_{1} \quad$ : "Mungkinkah itu? Mungkinkah Wickham akan menikahi Lydia?"

"Wickham tidak sejahat yang kau kira, kalau begitu. Ayahku sayang, selamat untukmu."

$\mathrm{BSa}_{2} \quad$ : "Mungkinkah itu? Mungkinkah Wickham akan menikahi Lydia?"

"Wickham tidak sejahat yang kau kira, kalau begitu. Ayahku sayang, selamat untukmu." 
Pada contoh di atas, jawaban Jane sebenarnya tidak ada hubungannya dengan pertanyaan Elizabeth. Selain itu, jawaban "My dear father, I congratulate you" menyiratkan sesuatu agar ayahnya jangan terlalu khawatir dengan Lydia yang sedang bersama Wickham. Dua hal itu lah yang membuat jawaban Jane tersebut melanggar violating maksim relevansi.

Hanya ditemukan 1 data yang tergolong pelanggaran violating maksim relevansi. Teknik yang digunakan dari kedua penerbit adalah kesepadanan lazim, peminjaman murni, dan variasi. Satu data dari pelanggaran violating maksim relevansi menghasilkan terjemahan yang kurang akurat dan kurang berterima dari novel Penerbit Shira Media dan Qanita.

\section{Pelanggaran Maksim Multiple}

Pelanggaran maksim multiple di sini ialah apabila penutur melanggar lebih dari 1 maksim PK, misalnya jika penutur mengatakan sesuatu yang tidak benar adanya dan berlebihan tidak sesuai porsinya. Terdapat 5 data yang termasuk dalam pelanggaran maksim multiple Contohnya adalah sebagai berikut:

BSu : "I have been making the tour of the park," he replied, "as I generally do every year, and intend to close it with a call at the Parsonage. Are you going much farther?"

"No, I should have turned in a moment."

$\mathrm{BSa}_{1} \quad$ : "Aku sedang mengelilingi taman, seperti yang biasa kulakukan setiap tahun, dan berniat mengakhiri kegiatan ini dengan bertamu di Parsonage. Apakah perjalananmu masih jauh?"

"Tidak, aku akan balik sebentar lagi."

$\mathrm{BSa}_{2} \quad$ : "Aku sedang mengelilingi taman, seperti yang biasa kulakukan setiap tahun, dan berniat mengakhiri kegiatan ini dengan bertamu di Parsonage. Apakah perjalananmu masih jauh?"

"Tidak, aku akan berbalik sebentar lagi."

Contoh di atas merupakan data yang melanggar maksim kuantitas dan kualitas. Pelanggaran maksim kuantitas dapat dilihat pada jawaban "I should have turned in a moment”. Sebenarnya Elizabeth tidak perlu memberikan jawaban itu karena 
Kolonel Fitzwillian tidak menanyakan hal itu. Selanjutnya, pelanggaran maksim kualitas dapat dilihat dari jawaban "No" yang sebenarnya Elizabeth belum akan meninggalkan taman saat itu. Ia hanya ingin menghindar dari Kolonel Fitzwilliam karena tidak ingin surat dari Jane diketahui oleh Konolel Fitzwilliam.

Pada temuan pelanggaran maksim multiple, ditemukan total 5 jenis teknik penerjemahan. Pada novel Penerbit Shira Media, teknik yang digunakan adalah kesepadanan lazim, variasi, amplifikasi (eksplisitasi), peminjaman murni, dan transposisi. Sedangkan pada novel Penerbit Qanita, teknik yang digunakan adalah kesepadanan lazim, variasi, amplifikasi (eksplisitasi), peminjaman murni, dan modulasi.

Dari 5 data dua versi novel tersebut, menghasilkan 2 terjemahan akurat dan 3 terjemahan kurang akurat. Namun dalam hal keberterimaan, hanya ditemukan 1 data yang tergolong kurang berterima.

\section{KESIMPULAN}

Dari hasil penelitian yang telah diuraikan diatas, kesimpulan yang dapat ditarik antara lain adalah:

1. Pada tuturan menjawab (TM) dalam 2 versi novel terjemahan Pride and Prejudice terdapat tuturan yang mematuhi maksim PK (46 data) dan melanggar maksim PK (89 data). Dari keseluruhan data, pelanggaran maksim yang paling sering muncul adalah flouting maksim kuantitas, yaitu penutur tidak memberikan kontribusi yang secukupnya atau sebanyak yang dibutuhkan oleh mitra tuturnya. Sebaliknya, pelanggaran maksim violating kualitas dan maksim cara tidak ditemukan pada data dalam penelitian ini. 
2. Ditemukan 13 jenis teknik penerjemahan dalam novel Penerbit Shira Media dan 11 jenis teknik penerjemahan dalam novel Penerbit Qanita. Teknik yang mendominasi pada dua versi novel terjemahan tersebut adalah teknik kesepadanan lazim, yaitu digunakan untuk menerjemahkan sesuatu yang terikat dengan konteks situasi dan tidak bisa diterjemahkan kata demi kata.

3. Mayoritas penggunaan teknik kesepadanan lazim, peminjaman, dan variasi berdampak pada terjemahan yang akurat dan berterima pada novel penerbit Shira Media dan Qanita. Sementara itu, kemunculan teknik harfiah dan kreasi diskursif menghasilkan terjemahan yang kurang akurat dan kurang berterima. Kurang akurat atau kurang berterimanya suatu terjemahan nampaknya dikarenakan penerjemah kurang tepat dalam mengaplikasikan teknik penerjemahan saat menerjemahkan tuturan menjawab.

\section{SARAN}

\section{Bagi Penerjemah}

Untuk mengetahui bahwa tuturan tersebut merupakan tuturan menjawab, penerjemah hendaknya diharapkan lebih memperhatikan konteks situasi tuturan tersebut. Hal itu juga dapat membuat penerjemah mengetahui teknik apa yang tepat untuk diaplikasikan dalam menerjemahkan tuturan yang sedang diterjemahkan, sehingga dapat menghasilkan terjemahan yang memiliki kualitas terjemahan yang baik.

Dalam menerjemahkan tuturan menjawab, penerjemah terkadang masih salah dalam memilih diksi yang tepat sesuai dengan yang dimaksud di bahasa sumber. Hal tersebut dapat mengakibatkan maksud tuturan yang ada di bahasa sumber menjadi berbeda dengan yang ada di bahasa sasaran. Sehubungan dengan hal itu, penerjemah 
hendaknya dapat lebih hati-hati dalam pemilihan diksi saat menerjemahkan tuturan menjawab. Pertimbangan konteks situasi, antara lain penutur dan mitra tutur yang terlibat dalam sebuah percakapan, juga waktu dan tempat berlangsungnya percakapan juga merupakan hal pokok yang seharusnya lebih diperhatikan oleh penerjemah. Terkadang keputusan penerjemah untuk mempertahankan bentuk atau pesan suatu terjemahan merupakan keputusan yang sulit untuk ditentukan. Dengan kata lain, penerjemah sulit memilih apakah ia harus mempertahankan keakuratan atau keberterimaan terjemahan. Namun penerjemah hendaknya selalu menyadari bahwa prinsip utama penerjemahan adalah sebagai suatu kegiatan pengalihan pesan dari bahasa sumber ke bahasa sasaran.

\section{Bagi peneliti lain di bidang ilmu linguistik penerjemahan}

Penulis menyadari bahwa aspek yang diteliti pada penelitian ini merupakan aspek yang masih kecil dari keseluruhan aspek yang berhubungan dengan linguistik, khususnya pragmatik dan penerjemahan. Peneliti berharap peneliti-peneliti lain dapat mengambil celah yang bisa dikembangkan lagi sehingga dapat mengeksplor lebih mengenai kajian tentang linguistik dan penerjemahan. Salah satu contohnya ialah mengkaji tindak tutur lain selain asertif dan diperluas cakupannya.

Selain itu, peneliti lain juga dapat menggunakan sumber data yang berbeda dari penelitian ini, misalnya terjemahan dalam bentuk subtitle dalam film atau dubbing. Dengan begitu, peneliti lain masih memiliki kesempatan untuk menggali lebih dalam sehubungan dengan tindak tutur dari sumber data yang berbeda.

Dalam kajian penerjemahan, penelitian ini hanya mengkaji teknik penerjemahan dan kualitas terjemahan. Masih terbuka kesempatan bagi peneliti lain 
untuk mengembangkan dua aspek penerjemahan lainnya pada tataran makro, yakni: metode penerjemahan dan ideologi penerjemahan. Dengan begitu, peneliti berharap kepada peneliti lain untuk dapat melanjutkan kajian terjemahan tersebut sehingga dapat menghasilkan temuan yang lebih rinci, luas, serta dapat menyentuh seluruh aspek dalam kajian penerjemahan.

\section{DAFTAR PUSTAKA}

Austen, Jane. 1813. Pride and Prejudice. New York: Barnes and Noble Publishing, 2003. (http://www.book4free.us/2014/02/pride-and-prejudice-by-jane-austenpdf.html)

Austen, Jane. 2014. Pride and Prejudice. Yogyakarta: Shira Media.

Austen, Jane. 2014. Pride and Prejudice. Bandung: Qanita.

Austin, J.L. 1962. How to do things with words. Harvard University Press. Baker, M. 1992. In other words: A coursebook on translation. London and New York: Routledge.

Bassnett, S. 1991. Translation Studies ( $2^{\text {nd }}$ ed). London: Routledge.

Bell, T. Roger. 1991. Translation and Translating: Theory and Practice. New York: Longman Inc.

Birner, Betty J. 2013. Introduction to Pragmatics. Blackwell

Brislin, R. W. 1976. Translation: Application and Research. New York: Gardner Press Inc.

Catford, J. C. 1974. A Linguistic Theory of Translation. London: Oxford UniversityPress.

Chaer, Abdul. 2004. Linguistik Umum. Jakarta : PT.Rineka Cipta.

Djajasudarma, Fatimah.2012.Wacana dan Pragmatik. Bandung:Rafika Aditama.

Griffiths, Patrick. 2006. An Introduction to English Semantics and Pragmatics. Edinburgh University Press.

Hymes, D. 1964. Language in Culture and Society. New York: Harper and Row

Kreidler, W. Charles. 1998. Introducing English Semantics. New York: Routledge. 
Kuncara, Singgih Daru. 2013. Analisis Terjemahan Tindak Tutur Direktif Pada Novel The Godfather dan Terjemahannya dalam Bahasa Indonesia. Surakarta: Universitas Sebelas Maret.

Lailiyah, Sufil. 2013. Tindak tutur direktif dalam rubrik reader's forum di The Jakarta Post. Yogyakarta: Universitas Gadjah Mada. (http://etd.ugm.ac.id/index.php?mod=penelitian_detail\&sub=PenelitianDetail\& act=view\&typ=html\&buku_id=63726\&obyek_id=4)

Leech, Geoffrey. 1993. Prinsip-prinsip Pragmatik. Jakarta: Universitas Indonesia Press

Levinson, Stephen C. 1983. Pragmatics. Cambridge: Cambridge University Press.

Limyana. 2011. Terjemahan tindak tutur asertif tokoh utama dalam novel The Kite Runner karya khaled hosseini. Surakarta: Universitas Sebelas Maret

Machali, Rochayah. 2000. Pedoman bagi penerjemah. Jakarta: Grasindo.

Molina, Albir \& Amparo Hutardo. 2002. Translation Techniques Revisited: A Dynamic and functionalist approach dalam Meta: Translation's journal XLVII, 4

Muhartoyo \& Kristani, Keylli. 2012. An analysis of directive speech acts in the movie "Sleeping Beauty". Jakarta: Universitas Bina Nusantara.

Nababan, M.R. 2003. Teori Menerjemah Bahasa Inggris. Yogyakarta: Pustaka Pelajar.

Nababan, Nuraeni, \& Sumardiono. 2012. Pengembangan Model Penilaian Kualitas Terjemahan. Surakarta: Universitas Sebelas Maret

Nadar, F. X. 2009. Pragmatik \& Penelitian Pragmatik. Yogyakarta: Graha Ilmu.

Newmark, Peter. 1998. A Textbook of Translation. Oxford: Pergamon Press.

Nida, E. A. \& Charless, C. R. 1982. The Theory and Practice of Translation. Leiden: E. J. Brill.

Nuraeni, Ardianna. 2008. Perbandingan terjemahan "tindak tutur mengeluh" dalam film Bad Boys II yang ditayangkan di stasiun televisi dan di VCD (kajian strategi penerjemahan, kesepadanan makna dan keberterimaan). Surakarta: Universitas Sebelas Maret.

Panuntun, Ida Ayu. 2012. Tindak tutur dan pelanggaran maksim percakapan pada novel Harry Potter and The Sorcere's Stone. Jurnal PENA Ilmu Pengetahuan dan Teknologi Edisi Maret 2012. Prodi PBI-FKIP Universitas Pekalongan. Vol 22 No.1 2012

Prananta, Alfian Yoga. 2015. Perbandingan terjemahan ujaran yang mengandung implikatur percakapan pada subtitle film kategori remaja The Avengers dan film kategori dewasa The Departed. Surakarta: Universitas Sebelas Maret 
Pratama, Ikke Dewi. 2014. Analisis perbandingan srategi kesantunan tuturan memerintah dalam film The Amazing Spiderman dan dua versi terjemahannya (subtitle VCD dan amatir) serta dampaknya pada kualitas terjemahan.

Surakarta: Universitas Sebelas Maret

Putranti, Adventina. 2007. Kajian terjemahan tindak tutur ilokusi ekspresif dalam teks terjemahan film “American Beauty”. Surakarta: Universitas Sebelas Maret.

Santosa, Riyadi. 2014. Metode penelitian kualitatif kebahasaan. Surakarta: Universitas Sebelas Maret.

Searle, John R. 1979. Expression and meaning. London: Cambridge University Press.

Shera, Yohana. 2014. Tindak tutur direktif anak dalam media kajian pragmatic surat pembaca rubrik “Apa Kabar, Bo?” pada majalah bobo". Yogyakarta: Universitas Gadjah Mada.

Spradley, James P. 2007. Metode etnografi. Yogyakarta: PT Tiara Wacana

Sutopo, H.B. 2002. Metodologi penelitian kualitatif. Surakarta: UNS Press.

Wahyuni, Ari. 2014. Analisis teknik penerjemahan tindak tutur direktif dalam film alice in wonderland dan pengaruhnya terhadap kualitas terjemahan. Surakarta: Universitas Sebelas Maret.

Widianingsih. 2015. Analisis terjemahan kalimat yang mengandung tindak Tutur predicting pada percakapan dalam novel "The Serpent's Shadow" karya rick riordan dan kualitas terjemahannya. Surakarta: Universitas Sebelas Maret

Wijana, Dewa Putu. 1996. Dasar-dasar pragmatik. Yogyakarta: ANDI

Yule, George. 1996. Pragmatics. New York: Oxford University Press.

http://www.biography.com/people/janeausten-9192819\#synopsis. Diakses 2 November 2015. 